Tropical Journal of Pharmaceutical Research, February 2010; 9 (1): 11-17

(C) Pharmacotherapy Group, Faculty of Pharmacy, University of Benin,

Benin City, 300001 Nigeria.

All rights reserved.

Research Article

Available online at http://www.tjpr.org

\title{
A Comparative Study of Quinine and Artemether in the Treatment of Severe Malaria in Nigerian Children
}

\author{
Cletus N Aguwa, Chinwe V Ukwe and Maxwell O Adibe*
}

Department of Clinical Pharmacy and Pharmacy Management, University of Nigeria, Nsukka, Nigeria.

\begin{abstract}
Purpose: Nigeria has adopted quinine as the drug of first choice in the treatment of severe malaria and artemether as an alternative therapy. The purpose of this study was to ascertain whether artemether is a comparable alternative to quinine in the management of severe malaria in Nigerian children.

Methods: We conducted a randomized prospective study comparing quinine and artemether therapies in 90 Nigerian children with severe malaria.

Results: Mortality was lower in quinine group (13.0\%) than artemether (15.9\%), Odds Ratio (OR) = 0.446 (95\% Confidence Interval $(\mathrm{Cl}), 0.124$ to 1.603, $p=0.249$ ). The parasitaemia clearance on day 3 by quinine and artemether was 96.8 and $99.0 \%(p=0.422)$, respectively, while on day 14 it was $100 \%$ for both medicines. Fever clearance by quinine and artemether was 87.7 and $90 \%(p=0.753)$, respectively, on day 3 but it increased to 100 and $96.42 \%(p=0.072)$, respectively, on day 14 . For the quinine group, $71.74 \%$ of the patients spent less than one week in the hospital versus $61.76 \%$ for the artemether group ( $p=0.829, O R=0.883,95 \% \mathrm{Cl}=0.284$ to 2.742 ).
\end{abstract}

Conclusion: Artemether is a comparable alternative to quinine in the treatment of severe paediatric malaria.

Key words: Artemether; Nigerian children; Paediatric; Quinine; Severe malaria. 


\section{INTRODUCTION}

Each year, worldwide, there are about 300 500 million clinical cases of malaria and an estimated $1.1-2.7$ million deaths as result of severe malaria [1]. Over $90 \%$ of deaths occur in children below 5 years of age, mainly from cerebral malaria in children 2 - 5 years and anaemia in children $0.5-2$ years [2]. Neurological sequelae persisting for more than 6 months occur in more than $2 \%$ of the survivors, and they include ataxia, hemiplegia, speech disorders, behavioural disorders, epilepsy and blindness. Severe malaria with anaemia has case fatality rate higher than $13 \%$ [3].

Of increasing concern is the declining efficacy of quinine in parts of southeast Asia [4], a trend that could prove disastrous if it spreads to Africa, where most deaths from malaria occur. Thus, there is an urgent need to identify new forms of therapy for severe malaria that are economical and practical alternatives to quinine and, ideally, improve the clinical outcome of severe malaria. Among potential alternatives to quinine, the artemisinin (qinghaosu) derivatives have attracted special interest because of the rapidity with which they reduce Plasmodium falciparum parasitaemia [5]. Nigeria has adopted parenteral quinine as the drug of first choice in the treatment of severe malaria and artemether as an alternative therapy [6]. Thus, in this study, we have compared the effectiveness of quinine and artemether in some Nigerian children.

\section{METHODS}

\section{Study setting}

This study was conducted in Federal Medical Centre, Birnin Kudu, Jigawa State of Nigeria. This is a heavily malaria-infested area, as a result of its ever growing population and the presence of many ponds, pools and rivers which serve as sources of water for domestic and agricultural purposes. Malaria is characterised by a stable, perennial, transmission in all parts of the state. The transmission of malaria is higher in the wet (rainy) season than in the dry season in the state, with a peak at the former from May to late September. The centre was chosen because it is the only tertiary health facility, the highest referral centre and also has better medical services and documentation than any other health facility in the state.

\section{Research design}

The children who met the inclusion criteria were enrolled in the study and randomly assigned to receive either quinine or artemether therapy. Patients were assigned to receive quininie if the last digit of their hospital identification number was odd and to receive artemether if the last digit of their hospital identification number was even or zero. This study was conducted from July 6 to October 24, 2007. This period was chosen because malaria transmission and hospital admission are usually high due to heavy rainfall during this period.

Children between 6 months and 12 years of age presenting with fever $\left(>37.5^{\circ} \mathrm{C}\right)$ and $P$. falciparum infection cases, with one or more general danger signs of severe or complicated malaria were included in the study based on the following definition of severe malaria [7]:

In a patient with $P$. falciparum asexual parasitaemia and no other obvious cause of their symptoms, the presence of one or more of the following clinical or laboratory features classifies the patient as suffering from severe malaria:

Clinical manifestation: Prostration, impaired consciousness, respiratory distress (acidotic breathing), multiple convulsions, circulatory collapse, pulmonary oedema (radiological), 
abnormal bleeding, jaundice and Haemoglobinuria.

Laboratory test: Severe anaemia, hypoglycaemia, acidosis, renal impairment, hyperlactataemia and hyperparasitaemia.

Excluded were patients with serious concomitant illness, e.g., sick cell anaemia, HIV, tuberculosis and other chronic diseases; patients without any manifestations of severe malaria; and patients with severe malnutrition and known hypersensitivity to one of the study drugs. In addition, children below 6 months and those above 12 years were not included.

Structured data collection form was used for collection of demographic characteristics, clinical and treatment variables. Laboratory report form was used for recording laboratory findings. The forms were filled by the appropriate personnel serving in the hospital. Forty-six children (28 females and 18 males) were included in the quinine treatment group and they received quinine $20 \mathrm{mg}$ salt $/ \mathrm{kg}$ body weight (bw) on admission (i.v. infusion or divided i.m. injection, as a loading dose), then $10 \mathrm{mg} / \mathrm{kg}$ bw every $8 \mathrm{~h}$; the infusion rate did not exceed $5 \mathrm{mg}$ salt/kg bw per hour. Fortyfour children (24 females and 20 males) were included in the artemether group and they received artemether $3.2 \mathrm{mg} / \mathrm{kg}$ bw i.m. given on admission, as a loading dose and then 1.6 $\mathrm{mg} / \mathrm{kg}$ bw per day for 2 days. Quinimax ${ }^{\circledR}$ injection manufactured by Sanofi and Paluther ${ }^{\circledR}$ injection manufactured by May and Baker were used in this study. A quantitative parasite count of asexual forms was performed (using the parasite/white blood cell count) at day 0 , day 3 and day 14 . The parasite clearance was taken as adequate clinical and parasitological response (ACPR) at days 3 and 14 .

Their body temperatures were taken two times daily during the admission. Fever clearance was taken as body temperature $\leq$ $37.5{ }^{\circ} \mathrm{C}$ after treatment had commenced. Pediatric Coma Scale (PCS) developed by
Simpson and Reilly $[8,9]$ was used to assess the consciousness of the patients at days 0 , 1, 2 and 3. Normal aggregate score adjusted for age according to Simpson and Reilly was: 0 - 6 months: 9; > 6 - 12 months: 11 ; > 1 - 2 years: 12 ; > 2 - 5 years: 13 ; > 5 years: 14 . Any patient who had aggregate score below his specified normal age adjusted score was taken to be comatose. Mortality was estimated by the number of patients that died in the hospital. Hospital bed-days were calculated by the actual number of days each patient spent in the hospital. The patients were admitted and treated within the study period.

\section{Data analysis}

Data analysis was performed using SPSS for Windows 13.0 (SPSS Inc., Chicago, IL). We used $\mathrm{X} 2$ tests to compare categorical data (Fisher exact for groups smaller than $n=5$ ). Continuous data were tested for normality (test for skewness, Shapira - Wilkoxon test for normality). Normally distributed data were analysed with independent samples T-tests, and non-normally distributed data with MannWhitney $U$ test. A two-tailed significance level of 0.05 was used. Multivariate regression analysis was performed to determine whether baseline characteristics were associated with the outcome of treatment. Age, weight, sex, severity, number of co-morbidities, initial parasite count, and initial temperature were entered into the model as linear variable or classified categories. Intention-to-treat analysis was applied.

\section{Ethical consideration}

Necessary clearance was obtained from the University of Nigeria Teaching Hospital ethical committee and written consent was also obtained from the children's care takers. Moreover, confidentiality was maintained during data collection and processing, and the procedures did not endanger or have adverse effects on the patients. 


\section{RESULTS}

A total of 90 children were included in the study, 46 were treated with quinine while 44 were treated with artemether. Two patients absconded in each group, representing 4.35 and $4.55 \%$ for quinine and artemether, respectively. Six of 46 children treated with quinine died in the hospital (13.04 \%), compared with 7 of 44 patients treated with artemether $(15.90 \%)$. Thirty-one of 38 children discharged in the quinine group came back for follow-up (81.58 \%) on day 14 , compared with 30 of 35 children discharged in the artemether group (85.70\%). Multivariate regression analysis showed that none of the baseline characteristics influenced the outcomes significantly; independent of these, the treatment group was the primary determinant of the study outcomes (Table 1). The clinical features on admission were similar in the two groups (Table 2).

Table 1: The results of multivariate regression analysis

\begin{tabular}{|c|c|c|c|c|c|c|c|c|c|}
\hline \multirow[t]{3}{*}{$\begin{array}{l}\text { Dependent } \\
\text { variables }\end{array}$} & \multicolumn{9}{|c|}{ Predictors ${ }^{*}$} \\
\hline & Constan & tant & Weight & Sex & Severity & $\begin{array}{l}\text { Co- } \\
\text { morbidity }\end{array}$ & $\begin{array}{l}\text { Body } \\
\text { Tem day } \\
0\left({ }^{\circ} \mathrm{C}\right)\end{array}$ & $\begin{array}{l}\text { Para } \\
\text { day } 0\end{array}$ & $\begin{array}{l}\text { CNS } \\
\text { day } 0\end{array}$ \\
\hline & \multicolumn{9}{|c|}{ Unstandardized coefficients (B) } \\
\hline $\begin{array}{l}\text { aBody temp } \\
\text { day } 3\left({ }^{\circ} \mathrm{C}\right)\end{array}$ & 7.45 & -0.68 & 0.41 & -3.44 & 0.29 & 0.32 & -0.97 & 2.96 & -3.844 \\
\hline $\begin{array}{l}{ }^{\mathrm{b}} \text { Body temp } \\
\text { day } 14\left({ }^{\circ} \mathrm{C}\right)\end{array}$ & 10.36 & 1.80 & 1.57 & 0.08 & -1.73 & 0.43 & -3.85 & 2.31 & 0.35 \\
\hline $\begin{array}{l}{ }^{c} \text { Haemoglobin } \\
\text { day } 14(\mathrm{~g} / \mathrm{dl})\end{array}$ & 8.87 & 2.05 & -0.25 & 1.53 & -3.49 & 0.29 & 0.19 & -0.06 & -2.96 \\
\hline $\begin{array}{l}\text { dParasite } \\
\text { density day3 }\end{array}$ & 11.27 & -0.71 & -0.995 & 1.68 & 2.51 & -2.98 & 0.94 & 0.37 & -0.81 \\
\hline $\begin{array}{l}{ }^{\mathrm{e}} \text { Parasite } \\
\text { density day } 14\end{array}$ & 4.54 & 2.30 & -1.16 & 0.50 & -0.52 & -3.62 & 0.95 & 0.46 & 1.158 \\
\hline $\begin{array}{l}\text { fHospital bed- } \\
\text { days }\end{array}$ & 7.45 & -3.47 & 0.56 & 2.34 & 0.14 & -0.43 & 3.76 & -0.67 & 0.164 \\
\hline $\begin{array}{l}\text { Conscious- } \\
\text { ness status } \\
\text { day } 3\end{array}$ & 5.92 & -0.16 & 0.17 & -0.77 & -3.22 & 0.45 & -0.88 & 2.80 & -1.736 \\
\hline \multicolumn{10}{|c|}{ 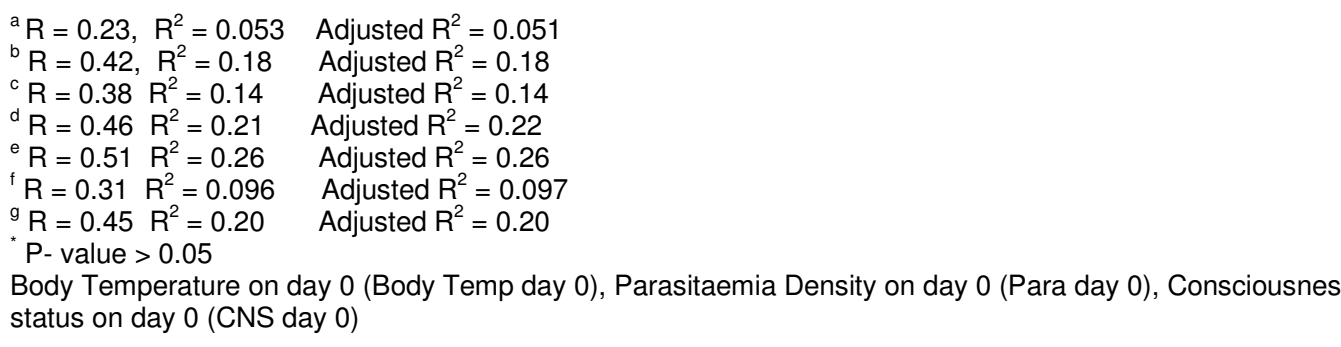 } \\
\hline
\end{tabular}


Aguwa et al

Table 2: Base-line demographic and clinical characteristics of the patients

\begin{tabular}{|c|c|c|}
\hline Characteristic & $\begin{array}{l}\text { Quinine } \\
\mathrm{N}=46\end{array}$ & $\begin{array}{l}\text { Artemether } \\
\mathrm{N}=44\end{array}$ \\
\hline${ }^{*}$ Age (years) & $3.2 \pm 1.7$ & $3.8 \pm 1.3$ \\
\hline "Sex, F/M (\%F) & 28/18(60.9) & $24 / 20(54.54)$ \\
\hline $\begin{array}{l}{ }^{*} \text { Mean weight }(\mathrm{kg}) \\
{ }^{\text {"Co-morbidities (\%) }}\end{array}$ & $14.74 \pm 8.42$ & $12.48 \pm 5.9$ \\
\hline Gastroenteritis & $17(36,96)$ & $20(45,46)$ \\
\hline $\begin{array}{l}\text { Acute upper respiratory tract } \\
\text { Infections }\end{array}$ & $12(26.01)$ & $8(23.53)$ \\
\hline $\begin{array}{l}\text { Acute lower respiratory tract } \\
\text { Infections }\end{array}$ & $2(4.35)$ & $4(9.09)$ \\
\hline None & $15(32.61)$ & 12(35.29) \\
\hline "Comatose patients (\%) & $10(21.74)$ & $7(15.90)$ \\
\hline $\begin{array}{l}\text { S Severe anaemia (haemoglobin }<5 \mathrm{~g} / \mathrm{dL} \text { ) } \\
(\%)\end{array}$ & $13(28.26)$ & $10(29.41)$ \\
\hline${ }^{*}$ Body temperature $\left({ }^{\circ} \mathrm{C}\right)$ & $38.27 \pm 0.51$ & $38.36 \pm 0.42$ \\
\hline $\begin{array}{l}* \text { Geometric mean of parasitaemia (per } \mu \mathrm{L} \\
\text { of blood) (range) }\end{array}$ & $\begin{array}{l}21,573.19(1,200- \\
210,000)\end{array}$ & $\begin{array}{l}27,268.43(1,200- \\
200800)\end{array}$ \\
\hline
\end{tabular}

${ }^{\pi}$ Frequency of patients (percentage); ${ }^{*}$ Mean $( \pm S D){ }^{*}$ Geometric mean (range)

Six of 46 children treated with quinine died in the hospital (13.04\%), compared with 7 of 44 patients treated with artemether $(15.90 \%)$; $\mathrm{RR}=0.446(95 \% \mathrm{Cl}, 0.124$ to $1.603, \mathrm{p}=$ 0.249). Most of the deaths occurred within the first 3 days of admission in both treatment groups; 61.54, 76.92 and $84.62 \%$ of these deaths occurred by days 1, 2 and 3 , respectively. Mortality was calculated based on the patients that died in the hospital.

Parasitaemia clearance of quinine on day 3 was (96.8 \%), compared with $99.0 \%$ clearance by artemether $(p=0.422)$ by Mann-Whitney test); however, parasitaemia clearance (ACPR) was (100\%) in both drug groups on day 14. The fever clearance of children treated with quinine and artemether were 87.7 and $90.0 \%(p=0.753)$ , respectively at day 3 , and 100 and $96.42 \%$ $(p=0.072)$ in quinine and artemether, respectively, at day 14 .

Although quinine showed greater effect on coma recovery on day 3 , there was no significant difference when the treatment groups were compared ( $p=0.763$ ) (Table 3$)$. The probability of recovering from coma in the artemether and quinine groups, respectively, was 0.43 and 0.50 within day 1 ; 0.71 and 0.80 within day 2 , and 0.86 and 0.90 within day 3 . The proportion of patients that spent less than one week in the hospital in quinine and artemether treatment groups were 71.74 and $61.76 \%$, respectively $(\mathrm{RR}=$ $0.883,95 \% \mathrm{Cl}, 0.284$ to $2.742, \mathrm{p}=0.829)$.

\section{DISCUSSION}

Quinine showed higher mortality prevention than artemether; the point estimate was consistent with quinine being associated with a massive $55 \%$ reduction in mortality risk vis a vis artemether. It had been widely anticipated that a more rapid reduction of parasitaemia would bring about a corresponding reduction in mortality. The odds ratios had wide confidence limits and one cannot exclude the possibility that artemether would reduce mortality if its use were widespread. Several smaller trials in southeast Asia suggested that treatment with artemisinin derivatives might reduce mortality by $50 \%$ [5]. Our finding suggests that the speed of parasite clearance may be a relatively unimportant determinant of survival. 
Table 3: Results of outcome parameters

\begin{tabular}{|c|c|c|c|c|c|}
\hline Outcome parameters & Artemether & Quinine & P-value & $\begin{array}{l}95 \% \\
\text { Confidence } \\
\text { Interval } \\
\end{array}$ & RR \\
\hline ¥Mortality & 20.59 & 13.04 & & 0.124 to 1.603 & 0.446 \\
\hline $\begin{array}{l}¥ \text { ¥oma Recovery } \\
\text { ð Parasitaemia clearance } \\
\text { on day } 3\end{array}$ & $\begin{array}{l}15.90 \\
(259 \pm 81) 99\end{array}$ & $\begin{array}{l}21.74 \\
(320 \pm 89) 96.8\end{array}$ & 0.422 & 0.065 to 9.015 & 0.763 \\
\hline $\begin{array}{l}\text { o Parasitaemia clearance } \\
\text { on day } 14\end{array}$ & $(122 \pm 23) 100$ & $(163 \pm 32) 100$ & 0.672 & & \\
\hline $\begin{array}{l}\text { "Fever clearance on day } \\
3 \text { (temperature } \leq 37.5^{\circ} \mathrm{C} \text { ) }\end{array}$ & $(37.0 \pm 0.4) 90$ & $(37.2 \pm 0.5) 88$ & 0.753 & & \\
\hline $\begin{array}{l}{ }^{9} \text { Fever clearance on day } \\
14 \text { (temperature } \leq 37.5 \\
{ }^{\circ} \mathrm{C} \text { ) }\end{array}$ & $36.9( \pm 0.5) 96.4$ & $37.3( \pm 0.3) 100$ & 0.072 & & \\
\hline $\begin{array}{l}\text { ПHospital bed-days } \\
\text { ( } \leq 7 \text { days) }\end{array}$ & $(7.1 \pm 1.6) 62$ & $(7.03 \pm 1.76) 71$ & & 0.284 to 2.742 & 0.883 \\
\hline
\end{tabular}

In this case, part of the explanation may be that artemether preferentially accelerates the clearance of younger parasites, which are those seen in the circulation, over more mature parasites, which are located deep in the vasculature and mediate organ damage [10].

The study revealed a shorter coma recovery time in the quinine group. There has been concern that artemether may be neurotoxic at high doses. This has been observed in studies in animals, but it is yet to be demonstrated in human beings [11]. The tendency toward a longer time to recovery from coma in the artemether group could possibly be due to such an effect.

This study showed that parasitaemia clearance on day 3 was higher in artemether group than in the quinine group. Although ACPR was $100 \%$ at day 14 in both groups, none of them completely eliminate the parasites. This study supports findings that both artemether and quinine lack the ability to prevent malaria re-infection $[12,13]$.

Fever clearance was higher in the artemether group than in the quinine group on day 3 and day14 but the difference was not significant.
This effect may be attributed to the relatively higher parasitaemia clearance exhibited by artemether as well as increasingly quinine resistance. The proportion of patients that spent less than one week in the hospital were higher in the quinine group than in the artemether group but the difference was not statistically significant. The greater parasitaemia clearance found in artemether did not reflect in the number of days spent in the hospital.

The World Health Organization currently recommends that artemisinin derivatives alone should not be used as first-line treatment in Africa, in order to delay the development of resistance to this valuable class of antimalarial compounds [14].

\section{Limitations of the study}

The following limitations were inherent in the study and the results were interpreted in this light. Fourteen days were not enough for a study of this kind because the true failure rates may have been higher. It has been estimated that 28-day assessments underestimate the true failure by about $20 \%$ for drugs with intermediate elimination halflife, such as lumefantrine and sulfadoxine- 
pyremethamine ( $3-6$ days half-life), and as much as $40 \%$ for drugs with a longer elimination half-life, such as desethylamodiaquine $[15,16]$. The sample size was small. Loss to follow-up was 18.4 and $14.3 \%$ in quinine and artemether respectively but losses were equally distributed between the two treatments. Some baseline characteristics were based on care takers' report, which might not be true.

\section{CONCLUSION}

This study has shown that quinine and artemether are comparable alternatives. Although quinine prevented mortality to a greater extent than artemether, other nonfatal measures of disease activity showed some similarity between the treatments. Using artemether as an alternative to quinine does not only provide alternative chemotherapy against severe malaria but should also help to preserve the other against ever-emerging antimalarial drug resistance by reducing exposure of either drug to parasites.

\section{REFERENCES}

1. World Health Organisation. WHO Expert Committee on Malaria: Twentieth Report, 1998. Geneva, Switzerland. World Health Organ Tech Rep Ser 2000; 892: i-v: pp 1-74.

2. Muphy GS, Oldfield EC. Falciparum malaria. Infect Dis Clin North Am 1996; 10: 747-755.

3. Murphy SC, Breman JG. Gaps in the childhood malaria burden in Africa: Cerebral malaria, neorological sequelae, anaemia, respiratory distress, hypoglycaemia, and complications of pregnancy. Am J Trop Med Hyg 2001; 64: S57-S67.

4. Pukrittayakamee S, Supanaranond W, Looareesuwan S, Vanijanonta S, White NJ. Quinine in severe falciparum malaria: evidence of declining efficacy in Thailand. Trans $R$ Soc Trop Med Hyg 1994; 88: 324-327.

5. Hien TT, White NJ. Qinghaosu. Lancet 1993; 341. 603-608.

6. Ministry of Health (May 2005). National Antimalarial Treatment Policy. Abuja- Nigeria; pp. 1-52.

7. World Health Organisation. Severe falciparum malaria. World Health Organisation, Communicable Diseases Cluster. Trans $R$. Soc. Trop. Med. Hyg. 2000; 94: S1-S90.

8. Simpson D, Reilly P. Paediatric Coma Scale. (Letter to the Editor). Lancet. 1982; 2: 450.

9. Reilly $P$, Simpson D.A, Sprod $R$, Thomas $L$. Assessing the conscious level in infants and young children: a paediatric version of the Glasgow Coma Scale. Child's Nerv Syst 1988; 4: 30-33.

10. White NJ. Clinical pharmacokinetics and pharmacodynamics of artemisinin and derivatives. Trans $R$ Soc Trop Med Hyg 1994; 88: Suppl 1:S41- S43.

11. Ingrid van den B., Christa K., Sarwatt Al A., François L., Manica B. and Jean-Paul G. Efficacy of three artemisinin combination therapies for the treatment of uncomplicated Plasmodium falciparum malaria in the Republic of Congo. Malaria Journal 2006, 5:113.

12. Salako LA, Walker O, Sowunmi A. Parenteral therapy of moderately severe malaria: comparison of intramuscular artemether and intramuscular sulfadoxine-pyrimethamine. Trans R Soc Trop Med Hyg 1994; 88: 89-91.

13. Nosten F, ter Kuile F, Thwai KL, Maelankirri L, White NJ. Spiramycin does not potentiate quinine treatment of falciparum malaria in pregnancy. Trans R Soc Trop Med Hyg 1993; 87:305-306.

14. Roll Back Malaria, World Health Organization and UNICEF. World malaria report 2005. Available at: http://rbm.who.int/wmr2005. (Accessed October 3, 2009)

15. Stepniewska K, Taylor WR, Mayxay M, Price R, Smithuis $F$, Guthmann JP, Barnes K, Myint HY, Adjuik M, Olliaro P, Pukrittayakamee S, Looareesuwan S, Hien T.T, Farrar J, Nosten $F$, Day NP, White NJ. In vivo assessment of drug efficacy against Plasmodium falciparum malaria: duration of follow-up. Antimicrob Agents Chemother 2004, 48: 4271-4280.

16. Bloland $P B$. Drug resistance in malaria. WHO/CDS/CSR/DRS Geneva, Switzerland; 2001. 